\title{
Spiralled Palliative Care Curriculum Aligned with International Guidelines Improves Self-Efficacy but Not Attitudes: Education Intervention Study
}

\author{
Amanda Landers (D) \\ Tim J Wilkinson (D) ${ }^{1,2}$ \\ 'Department of Medicine, University of \\ Otago, Christchurch, New Zealand; \\ ${ }^{2}$ Canterbury District Health Board, \\ Christchurch, New Zealand
}

\begin{abstract}
Purpose: Despite recommendations that palliative care education should be in all health professional programmes, such education is ad-hoc and variable. To reduce variability, the European Association of Palliative Care (EAPC) published a comprehensive guideline for curricula development. This study evaluates a new palliative and end-of-life care course for medical undergraduates aligned with the EAPC guidelines, focusing on knowledge, skills and attitudes.
\end{abstract}

Methods: Final-year medical students were surveyed using two validated questionnaires: Self Efficacy in Palliative Care (SEP-C) and Thanatophobia scale (TS). We compared the intervention group, that were exposed to an integrated palliative medicine course throughout the three clinical years, with a control group that were not exposed to the new educational intervention.

Results: For self-efficacy, the intervention group had statistically significantly higher scores than the control arm. The control group had high scores compared with international data. Positive attitudes to dying patients were low and did not differ between the two groups.

Conclusion: A well-designed palliative and end-of-life curriculum that is aligned to EAPC guidelines increases the self-efficacy of medical students in managing palliative patients but has little effect on attitudes to dying people. This is likely to be influenced by other factors such as the need for experiential learning.

Keywords: palliative care, curriculum development, self-efficacy, attitudes

\section{Plain Language Summary}

Palliative care is an essential part of the medical undergraduate programme; however, it is taught in an ad-hoc and variable way throughout the world. This study found a co-ordinated palliative and end-of-life care programme increases knowledge and skills but may not improve attitudes. The University of Otago undergraduates reported high confidence in patient management, symptom management and team attributes compared to other countries. Palliative care undergraduate courses are likely to require several experiential learning opportunities with patients to improve attitudes to dying people. More research of the junior doctor years may highlight if experience is the missing factor to develop positive attitudes.

\section{Introduction}

Correspondence: Amanda Landers University of Otago, 2 Riccarton Ave, Christchurch Central, Christchurch,

$801 \mathrm{I}$, New Zealand

Tel +6433640530

Email amanda.landers@otago.ac.nz
In 2017, the Lancet Commission on universal access to palliative care and appropriate analgesia recommended that all health professionals involved in the care of patients with advanced, progressive illness receive basic palliative and pain 
management training. ${ }^{1}$ The palliative approach strives to maintain quality of life for people facing life-limiting illness, in collaboration with families and carers. ${ }^{1}$ Palliative care looks beyond the biomedical model with a focus on the emotional, social and spiritual dimensions of a person with a life-limiting illness. It requires the acquisition of knowledge and skills to help manage this vulnerable population. Parallel to expertise in managing life-limiting illness is the attitude of health care workers towards the dying patient. $^{2}$

For the last 20 years, medical schools have grappled with how to integrate palliative care teaching into already overcrowded curricula. Undergraduate programmes from around the world report a wide range of dedicated palliative care curricular time from less than an hour to over 50 hours. $^{3-5}$ Undergraduate medical programmes are designed to impart knowledge and develop skills in core competencies. A recent systematic literature review of the effectiveness of undergraduate palliative care teaching has shown improved knowledge of students. ${ }^{6}$ Despite attempts to improve palliative care teaching in medical schools, newly qualified doctors tend to feel unprepared and report little interaction with dying patients in their undergraduate programmes. ${ }^{7}$ Attitudes to the dying patient directly impact the care a person receives at such a vulnerable time. Increased knowledge and training promotes confidence in a person's ability to meet learning objectives and, according to Bandura's theory of self-efficacy, ${ }^{8}$ this then encourages action. In contrast, a lack of self-confidence in caring for those with palliative care needs leads to avoidance of those situations with potential for poor health outcomes. $^{8}$

In 2013, the European Association for Palliative Care (EAPC) proposed recommendations for undergraduate education. ${ }^{9}$ One of the major goals was to change attitudes towards the care of those with advanced disease and their families. They advised curriculum developers that palliative care should be "vertically integrated" throughout the whole undergraduate medical programme. Vertical integration describes the concept of weaving palliative care teaching throughout the multiple years of medical school. The spiralled curriculum refers to the increasing complexity and integration of the learning objectives as medical students advance towards graduation. The learning outcomes prioritised by the EAPC included the basics of palliative care, pain and symptom management, indigenous health, psychosocial and spiritual needs, communication, teamwork and medico-legal and ethical issues. ${ }^{9}$ The EAPC recommended the teaching should include people from different professional backgrounds using a variety of methods including experiential learning and debriefing, discussion, role play and problem-based scenarios. A total of 40 hours training was suggested for achieving the goals of the curriculum.

In New Zealand, there are currently two medical schools, each of 6-years duration. The University of Otago Medical School students are spread across three campuses for their clinical years 4-6 (Dunedin, Wellington and Christchurch). In 2017, the Palliative and End-of-Life Module (PEOLC) commenced at the Christchurch campus. The creation of the integrated course allowed many of the principles of the EAPC curriculum to be instituted, including vertical integration, teaching from a variety of professions, different methods of delivery and some preliminary assessment.

This study aims to evaluate a new and spiralled palliative and end-of-life care programme for medical students integrated through the years $4-6$ at the University of Otago, Christchurch, New Zealand.

\section{Methods Study Participants}

The study took place at Otago Medical School, Christchurch campus between 2017 and 2019. Ethical approval was obtained from the University of Otago Ethics Committee. The participants were all final-year medical students about to newly qualify as doctors. Convenience sampling of this population was utilised. The control group consisted of the first two years of students $(2017,2018)$ who did not have the PEOLC module. This allowed baseline data to be collected. The intervention group (2019) was the first group of students to experience the full spiralled integrated palliative care course woven throughout the three clinical years. Over the study period, there was no change in admission criteria, assessments or completion rates for the programme, reassuring the research team that the cohorts were otherwise similar.

\section{Context}

The medical undergraduate degree at University of Otago is six years, with the three early learning years in Dunedin. The first year is general Health Science focused on the basics of health. Students enter medical school at the completion of 
the first year or as graduates from another degree. The next two years have sessions in the curriculum on the principles and philosophy of palliative care, models of care, the role of spirituality in end-of-life situations, communication in palliative settings, collaborative decision-making and medicoethical issues. The class is divided into three campuses in different cities for the clinical years 4-6.

\section{Palliative and End-of-Life Care Intervention}

The PEOLC programme was commenced at one campus (Christchurch) in 2017. It was designed as a spiral course over years 4, 5 and 6 . In the fourth year, the teaching was exclusively run by an academic specialist in palliative care with tutoring support from other specialties and disciplines such as nursing and dietetics. Five 2-hour teaching sessions were spread over the year and focused on the physiology of dying, goals of care, symptom management, cost of caring and the last days of life. The sessions were twice in the same week, with half the class at each time slot. The teaching incorporated interactive lectures, video clips, small group work, visiting community carers and cases. Additionally, the students visited a hospice for 4 hours in groups of 2-4 and spoke with an inpatient when possible. Each session had specified learning outcomes that were made available to the students.

In the fifth year, a further five 2-hour teaching sessions were integrated with other courses such as pharmacology, ethics, professional skills and Hauora Māori (Indigenous Health). This included a simulation session on how to break bad news. In the final year, there was a one-hour teaching session on prescribing for patients at the end of life and a more advanced session on symptom management at the end of life. The teaching methods were varied and included mixed media, lectures, small group discussion, cases, assigned readings and role play. Summative assessment was not part of the module, but a palliative medicine question could be part of the final examinations in the fifth year.

\section{Study Design}

The intervention group received dedicated teaching on specific palliative medicine topics by a medical specialist in the field. The control group learnt about end-of-life topics from specialties in an ad hoc way with less explicit learning outcomes. They had minimal exposure to palliative medicine specialists and their approach to life-limiting illness. Both groups received the year 2-3, largely didactic, curriculum.

Both groups were surveyed using questionnaires - for the control group, this was with paper surveys prior to the final teaching session in the sixth year. The intervention group were given the same surveys after their final teaching session. The distribution of the questionnaires occurred at the same time of year. However, in the intervention group, the information was gathered after the teaching session as that concluded the new PEOLC module. Informed consent was obtained from all participants. An electronic survey link was also sent out so that students who were overseas on elective or unwell at the time of the survey could be included. The electronic and written responses were combined.

\section{Data Collection Demographics}

The demographic section of the survey asked participants which pathway they had entered medical school through first year University Health Sciences, graduate entry or other. There was also a question regarding the amount of involvement with dying patients over the preceding 12 months with options of never, 1-3 patients, 3-5 patients or over 5 patients. The respondents were also asked how often they had been involved in multidisciplinary discussions about the palliative and end-of-life needs of patients and families, with options of never, rarely, sometimes or regularly.

\section{Questionnaires}

The Self-Efficacy in Palliative Care Scale (SEP-C) is a validated 23-item self-assessment survey that asks about various aspects of management in end-of-life situations. ${ }^{10}$ The scale has three different subscales:

1. Communication (8 items)

2. Pain and symptom management (8 items)

3. Multidisciplinary teamwork (7 items)

Each subscale outlines target attitudes and knowledge. Respondents are asked to self-rate their confidence in the behaviours and tasks on a $0-100$ visual analogue scale with the lower answers indicating anxiety or lack of confidence.

The Thanatophobia scale (TS) is also a validated questionnaire, which has seven questions using 7-point Likert scales and investigates the attitudes of the respondent towards possible scenarios that occur when caring for a dying patient. ${ }^{11}$ This includes feeling uneasy, or helpless 
when patients are facing serious outcomes. The answers range from 1 (strongly agree) to 7 (strongly disagree). The lower numbers equate to better attitudes and less discomfort with this group of patients.

\section{Data Analysis}

Data analyses were undertaken using the software Statistical Package for the Social Sciences (SPSS Inc., Chicago, IL, version 23). The mean and standard deviation (SD) of the subscales of SEP-C and each question of TS were calculated. Data for the control group was compared to the intervention group. Differences on the SEP-C and TS between the control and intervention groups were compared using a parametric independent $t$-test. Effect sizes were determined in the conventional way by expressing differences in means as a proportion of the standard deviation. Additional comparisons were made on the least exposed group of students; those who saw $<3$ palliative care patients in their final year and never or rarely were involved in multidisciplinary team discussions compared with those who participated with multiple patients and planning meetings. All incomplete questionnaires were excluded from analysis. A $p$ value $<0.05$ was considered to indicate a statistically significant result.

\section{Results}

\section{Demographics}

The control group consisted of 91 students in 2017 with a response rate of $57 \%(\mathrm{n}=52)$ and three excluded due to incomplete data and 109 students in 2018 with a $49 \%(n=53)$ response with one excluded. This led to a control group of 101 students. The intervention group consisted of 100 students with a response rate of $60 \%(\mathrm{n}=60)$. Two responses were excluded due to missing data, leaving 58 responses. In all three years, health science entry into medicine was over $75 \%$ of the cohorts $(82 \%, 85 \%, 76 \%)$, followed by a small number of graduate entry respondents $(12 \%, 13 \%, 12 \%)$.

Those with little involvement with palliative patients and family discussions were grouped together as a least exposed cohort. The least exposed group comprised 23 students (23\%) in the control group and 17 students in the intervention cohort (29\%). In 2017, two students self-reported that they never had involvement with the care of a dying patient. This increased to six students in 2018 and 14 respondents in 2019. The number of students with no involvement in multidisciplinary team discussions about palliative and end-of-life care needs with patients and families was reasonably static with eight students in 2017, six in 2018 and five in 2019.

\section{Self-Efficacy in Palliative Care}

Table 1 compares the control and intervention groups on self-efficacy. The self-reported self-efficacy scores were significantly higher in the intervention group for all three subscales: communication, patient management and multidisciplinary teams. The effect sizes were $0.4-1.1$ suggesting large to moderate effects.

\section{Thanatophobia}

Table 2 compares the control and intervention groups on attitudes of students towards dying people. The introduction of the PEOLC module did not change the attitudes of students towards dying people. However, the group least exposed to patients with end-of-life care needs tended to

Table I Self-Efficacy Questionnaire Outcomes for the Control Group and the Intervention Group with the Higher Scores Representing Greater Self-Efficacy

\begin{tabular}{|c|c|c|c|c|c|c|c|}
\hline SEP-C & $\mathbf{N}$ & Mean & SD & $t$ value & p value & Mean Diff & Effect Size $(\partial)$ \\
\hline \multicolumn{8}{|c|}{ SEP-C-Communication } \\
\hline Control & 101 & 47.51 & 15.73 & -2.37 & & & \\
\hline Intervention & 58 & 53.42 & 14.10 & -2.44 & 0.016 & -5.91 & 0.40 \\
\hline \multicolumn{8}{|c|}{ SEP-C-Patient Management } \\
\hline Control & 101 & 47.14 & 13.42 & -6.45 & & & \\
\hline Intervention & 58 & 60.98 & 12.27 & -6.60 & 0.000 & -13.83 & I.I \\
\hline \multicolumn{8}{|c|}{ SEP-C- Multi-disciplinary Teams } \\
\hline Control & 101 & 48.39 & 15.79 & -4.32 & & & \\
\hline Intervention & 58 & 59.23 & 14.16 & -4.45 & 0.000 & -10.84 & 0.72 \\
\hline
\end{tabular}


Table 2 Thanatophobia Questionnaire Outcomes for the Control Group and the Intervention Group with the Lower Scores Representing Improvement in Attitudes

\begin{tabular}{|l|c|c|c|c|c|c|}
\hline Thanatophobia & N & Mean & SD & p value & Mean Diff & Effect Size \\
\hline Control & 101 & 3.08 & 0.95 & & & \\
\hline Intervention & 58 & 2.94 & 0.84 & 0.36 & 0.14 & 0.16 \\
\hline Least exposed Control & 23 & 3.35 & 1.03 & & & \\
\hline Least exposed Intervention & 17 & 3.15 & 1.10 & 0.18 & 0.20 & 0.18 \\
\hline
\end{tabular}

have poorer attitudes. The effect sizes were $0.16-0.18$ suggesting small effects.

\section{International Comparisons}

The SEP-C and Thanatophobia validated scales have been utilised in the setting of undergraduate medical students and their palliative care teaching across the world. It is therefore possible to compare the intervention and control groups to other developed countries. Scores from our intervention group compare favourably with other countries with only the UK scoring more highly, although teamwork scores were higher than the UK (but lower than Spain) (Figure 1). In contrast, the intervention group had poorer attitudes (higher scores) to dying patients than the United Kingdom, Spain, Ireland and France (Figure 2). The majority of these European studies were undertaken in newly qualified doctors after completion of medical school. The Australian data are from mid-way through their training.

\section{Discussion}

Despite recommendations that palliative care education should be included in all health professional programmes, such education is often ad hoc and variable. ${ }^{12-15}$ Our study has shown that a well-designed palliative and end-of-life curriculum aligned to EAPC guidelines increases the confidence and self-efficacy of medical students in managing palliative patients. ${ }^{9}$ However, the curriculum appeared to have little effect on attitudes to dying people. Our research suggests that lower exposure to dying patients may be associated with worse attitudes to dying people. This study also indicates that after experiencing the integrated PEOLC curriculum, our students had some of the highest ratings of reported self-efficacy in the world, and they also showed moderate-to-large effect sizes. In explaining the lesser effect on attitudes to dying people, we suggest two possibilities. The first, as suggested by our results, is that these attitudes may be more influenced by experience those students less exposed to dying people had poorer attitudes. It is therefore possible that these attitudes may change after graduation - an area worthy of future research. Alternatively, it is possible that students bring with them their own cultural beliefs and backgrounds that will influence their attitudes to dying. These are less likely to be altered by any curriculum.

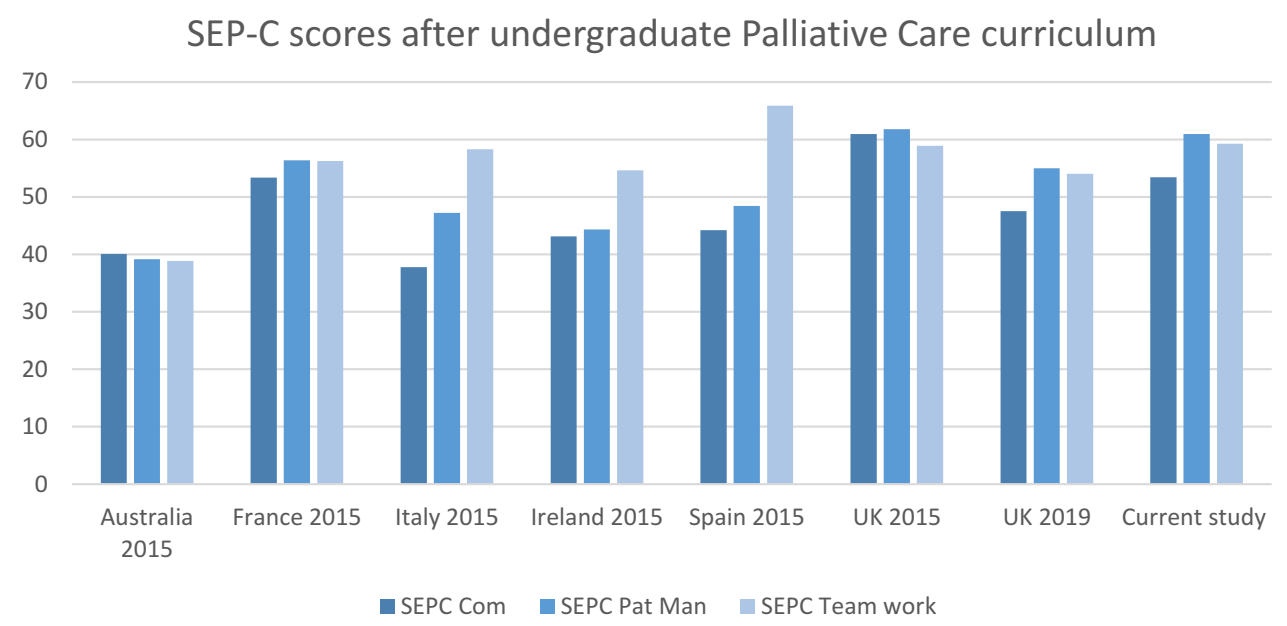

Figure I The SEP-C scores per country for communication, patient management and team work with the higher scores representing high self-efficacy. 


\section{Thanatophobia scores after undergraduate Palliative Care curriculum}

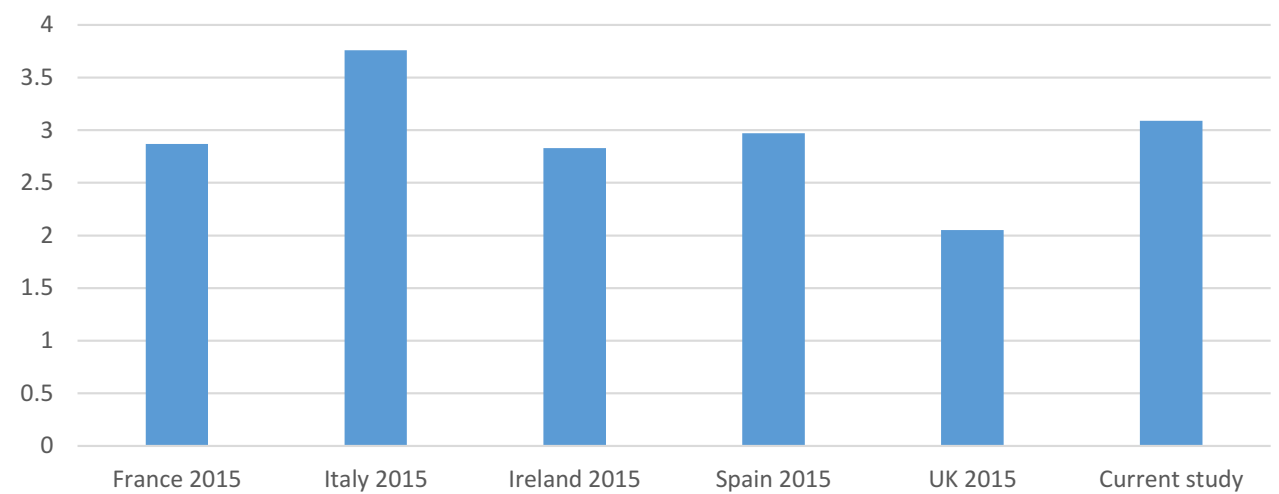

Figure 2 The Thanatophobia scores per country with higher scores representing worse attitudes towards dying people.

\section{Comparison with Existing Literature}

Others have found a spiralled palliative medicine curriculum, with repeated exposure to relevant topics and concepts, works to improve knowledge and skills in end-of-life care. ${ }^{16}$ Various formats, interventions, lengths and teaching methods are effective, with most curricula made up of didactic or interactive lectures and small group teaching. ${ }^{17-19}$ There did not appear to be one teaching method more successful than any other in the undergraduate curriculum, although we would suggest a variety of methods seems effective. ${ }^{6}$

Although knowledge and skills are critical to excellent patient care, attitudes to those with life-limiting illness also play a vital role in the quality of health care provision. Attitudes towards death and dying impact the way doctors care at the end of life. ${ }^{20}$ Here, we suggest experiential learning is likely to be effective. ${ }^{21,22}$ This is based on our own results, where those with less exposure had poorer attitudes. Also, a qualitative study of newly qualified doctors in the UK found multiple factors had played a role, but the most influential was the perceived lack of exposure to patients with life-limiting illness. ${ }^{21}$ Anderson et al compared first-year graduates with students in their first month of medical school. ${ }^{23}$ Participants who reported personal or professional experience with death were more likely to have positive attitudes about the responsibilities of doctors and the ability to care for this patient population.

Sweeney et al assessed the educational impact of a palliative care module in Ireland on medical students, particularly focused on knowledge, skills and attitudes. ${ }^{17}$ They also used the SEP-C and Thanatophobia tools utilised in our study. Their students were mid-way through their medical school training and were offered an elective module consisting of 12 weekly 2-hour sessions with a range of teaching methods, which included lectures, small group discussions, role-play and case studies. This aligns closely with our curriculum in teaching style but not timing. Sweeney et al obtained similar results to our study with significant improvements in skills and knowledge, but not attitudes. Experiential learning appears to be the key. ${ }^{24,25}$

The question is then raised about timing and length of clinical experiences required to improve attitudes to the dying patient. Mason et al developed two parallel curricula, six versus nine days of inpatient palliative care experience and found no difference between the two formats. ${ }^{19}$ Both cohorts had improved SEP-C and Thanatophobia scores equally well. Simulation also improved medical student attitudes towards end-of-life care in an Irish study. They report $2 \times 25$ minutes of simulation had a positive impact and is therefore a viable alternative to clinical exposure. In a regional or rural area, outside of the big teaching hospitals, this may be explored further as a way of exposing medical students to the patient with life-limiting illness.

On a global scale, the UK appears to have the most effective curricula with high SEP-C scores and low TS scores suggesting positive attitudes towards dying people. ${ }^{26}$ The success of these curricula are speculation but may be, in part, the prioritisation of palliative medicine teaching. ${ }^{27}$ Furthermore, care of the person with a lifelimiting illness is integral to the UK health system and has been for several decades. This integration has allowed palliative medicine role models and champions to rise up within the health system, to develop educational strategies and identify opportunities for reform. It is in this context that 
UK medical students learn end-of-life care, in what is effectively an apprenticeship model. The less successful curricula appear to begin with didactic or small group teaching but lack authentic experiences of palliative care in their training.

\section{Strengths and Weaknesses of the Study}

The value of this study lies in both assessing the success of a spiralled palliative medicine curriculum in a New Zealand context on skills and knowledge, and revealing the need for experiential learning for true attitude change. A further strength is the inclusion of a control group for comparison. The limitations of the study include the single-centre design and the inability to tease out the elements of the curriculum that have allowed for the greatest impact on the students.

\section{Implications for Future Practice}

In our study, the benefit of dedicated teaching time which focused on identification of the dying patient, symptom management and communication was obvious and measurable. The exposure, however, to patients varied widely and appeared to be worsening through the study period. Experiential learning that is more likely to occur in a spiralled or longitudinal format has positive impacts on learning and skill development. ${ }^{16,28}$ This study suggests undergraduate palliative medicine curricula should focus on teaching the concepts and content of endof-life care but also provide several opportunities to experience the care required for a quality death.

\section{Conclusions}

An appropriately resourced, designed and integrated medical education programme as recommended by the Lancet Commission equips senior medical students with basic skills in palliative care. Dedicated time in the curriculum to palliative medicine during the clinical years results in statistically significant improvements in communication, symptom management and multidisciplinary care. A spiralled course with relevant topics improves knowledge and skills but has little impact on the attitudes of medical student to the dying patient. Impact on attitudes is likely to require experiential learning beyond just one or two sessions, sustained throughout at least a week of clinical placement in appropriate settings.

\section{Data Sharing Statement}

Data are available upon request. It is not in a repository state but is available on request from the lead author. It is de-identified. Author can be contacted on amanda.landers@otago.ac.nz.

\section{Ethics Approval}

Ethical approval for this study was obtained from the University of Otago Human Ethics Committee (D17/245).

\section{Acknowledgments}

The authors acknowledge Prof Chris Frampton for help with the statistical analysis and Stella Lisle for data input.

\section{Author Contributions}

AL and TW were both involved in the design of the study. AL collected the data and completed the analysis. AL and TW interpreted the results and discussed the conclusions, and both were involved in drafting the manuscript. Both revised or critically reviewed the article; gave final approval of the version to be published; agreed on the journal to which the article has been submitted; and agreed to be accountable for all aspects of the work.

\section{Funding}

This research received no specific grant from any funding agency in the public, commercial, or not-for-profit sectors.

\section{Disclosure}

The authors report no conflicts of interest in this work.

\section{References}

1. Sepúlveda C, Marlin A, Yoshida T, et al. Palliative care: the World Health Organization's global perspective. J Pain Symptom Manage. 2002;24(2):91-96. doi:10.1016/S0885-3924(02)00440-2

2. Barnett MD, Reed CM, Adams CM. Death attitudes, palliative care self-efficacy, and attitudes toward care of the dying among hospice nurses. J Clin Psychol Med Settings. 2021;28(2):295-300.

3. DeCoste-Lopez J, Madhok J, Harman S. Curricular innovations for medical students in palliative and end-of-life care: a systematic review and assessment of study quality. J Palliat Med. 2015;18(4):338-349. doi:10.1089/jpm.2014.0270

4. Lehto JT, Hakkarainen K, Kellokumpu-Lehtinen P-L, et al. Undergraduate curriculum in palliative medicine at Tampere University increases students' knowledge. BMC Palliat Care. 2017;16(1):1-9. doi:10.1186/s12904-016-0182-8

5. Walker S, Gibbins J, Paes P, et al. Palliative care education for medical students: differences in course evolution, organisation, evaluation and funding: a survey of all UK medical schools. Palliat Med. 2017;31 (6):575-581. doi:10.1177/0269216316671279

6. Boland JW, Brown MEL, Duenas A, et al. How effective is undergraduate palliative care teaching for medical students? A systematic literature review. BMJ Open. 2020;10(9):e036458. doi:10.1136/bmjopen-2019-036458

7. Bowden J, Dempsey K, Boyd K, et al. Are newly qualified doctors prepared to provide supportive and end-of-life care? A survey of foundation year 1 doctors and consultants. $J R$ Coll Physicians Edinb. 2013;43(1):24-28. doi:10.4997/JRCPE.2013.105

8. Bandura A, Freeman W, Lightsey R. Self-Efficacy: The Exercise of Control. Springer; 1999. 
9. Elsner F, Centeno C, Cetto G, et al. Recommendations of the European Association for Palliative Care (EAPC) for the development of undergraduate curricula in palliative medicine at European medical schools; 2013.

10. Mason S, Ellershaw J. Assessing undergraduate palliative care education: validity and reliability of two scales examining perceived efficacy and outcome expectancies in palliative care. Med Educ. 2004;38(10):1103-1110. doi:10.1111/j.1365-2929.2004.01960.x

11. Merrill J, Lorimor R, Thornby J, et al. Caring for terminally ill persons: comparative analysis of attitudes (thanatophobia) of practicing physicians, student nurses, and medical students. Psychol Rep. 1998;83(1):123-128. doi:10.2466/pr0.1998.83.1.123

12. Charlton R, Currie A. A UK perspective on worldwide inadequacies in palliative care training: a short postgraduate course is proposed. Am JHosp Palliat Care. 2008;25(1):63-71. doi:10.1177/1049909107307389

13. Abel J, Kellehear A. Palliative curriculum re-imagined: a critical evaluation of the UK palliative medicine syllabus. Palliat Care Res Treat. 2018;11:1178224218780375.

14. Chiu N, Cheon P, Lutz S, et al. Inadequacy of palliative training in the medical school curriculum. J Cancer Educ. 2015;30(4):749-753. doi:10.1007/s13187-014-0762-3

15. White N, Oostendorp LJ, Minton O, et al. Palliative care training in undergraduate medical, nursing and allied health: a survey. $B M J$ Support Palliat Care. 2019. doi:10.1136/bmjspcare-2019-002025

16. Denney-Koelsch EM, Horowitz R, Quill T, et al. An integrated, developmental four-year medical school curriculum in palliative care: a longitudinal content evaluation based on national competency standards. J Palliat Med. 2018;21(9):1221-1233. doi:10.1089/ jpm.2017.0371

17. Sweeney C, Lynch G, Khashan A, et al. The impact of a medical undergraduate student-selected module in palliative care. BMJ Support Palliat Care. 2014;4(1):92-97. doi:10.1136/bmjspcare2012-000283

18. Gerlach C, Mai S, Schmidtmann I, et al. Does interdisciplinary and multiprofessional undergraduate education increase students' self-confidence and knowledge toward palliative care? Evaluation of an undergraduate curriculum design for palliative care at a German academic Hospital. J Palliat Med. 2015;18(6):513-519. doi:10.1089/jpm.2014.0337
19. Mason SR, Ellershaw JE. Undergraduate training in palliative medicine: is more necessarily better? Palliat Med. 2010;24(3):306-309. doi:10.1177/0269216309351867

20. Barclay S, Whyte R, Thiemann P, et al. An important but stressful part of their future work: medical students' attitudes to palliative care throughout their course. J Pain Symptom Manage. 2015;49 (2):231-242. doi:10.1016/j.jpainsymman.2014.06.004

21. Gibbins J, McCoubrie R, Forbes K. Why are newly qualified doctors unprepared to care for patients at the end of life? Med Educ. 2011;45 (4):389-399. doi:10.1111/j.1365-2923.2010.03873.x

22. MacLeod RD, Parkin C, Pullon S, et al. Early clinical exposure to people who are dying: learning to care at the end of life. Med Educ. 2003;37(1):51-58. doi:10.1046/j.1365-2923.2003.01412.x

23. Anderson WG, Williams JE, Bost JE, et al. Exposure to death is associated with positive attitudes and higher knowledge about end-oflife care in graduating medical students. J Palliat Med. 2008;11 (9):1227-1233. doi:10.1089/jpm.2008.0058

24. Brand AH, Harrison A, Kumar K. "It was definitely very different": an evaluation of palliative care teaching to medical students using a mixed methods approach. J Palliat Care. 2015;31(1):21-28. doi:10.1177/082585971503100104

25. Mason S, Ellershaw J. Preparing for palliative medicine; evaluation of an education programme for fourth year medical undergraduates. Palliat Med. 2008;22(6):687-692. doi:10.1177/0269216308090070

26. Mason S, Biasco G, Blumhuber H, et al. International Medical Education in Palliative Care: Pilot Research on Undergraduates (IMEP). Liverpool, UK: The Marie Curie Palliative Care Institute; 2015.

27. Quill TE, Dannefer E, Markakis K, et al. An integrated biopsychosocial approach to palliative care training of medical students. J Palliat Med. 2003;6(3):365-380. doi:10.1089/109662103322144682

28. Barrington DL, Murrie DA. A preceptor model for introducing undergraduate medical students to palliative medicine. J Palliat Care. 1999;15(1):39-43. doi:10.1177/082585979901500106
Advances in Medical Education and Practice

\section{Publish your work in this journal}

Advances in Medical Education and Practice is an international, peerreviewed, open access journal that aims to present and publish research on Medical Education covering medical, dental, nursing and allied health care professional education. The journal covers undergraduate education, postgraduate training and continuing medical education including emerging trends and innovative models linking education, research, and health care services. The manuscript management system is completely online and includes a very quick and fair peer-review system. Visit http://www.dovepress.com/testimonials.php to read real quotes from published authors. 